\title{
O Impacto do Gerenciamento de Reclamações na Confiança e na Lealdade do Consumidor
}

\author{
Cristiane Pizzutti dos Santos \\ Carlos Alberto Vargas Rossi
}

\section{Resumo}

O objetivo central deste trabalho é examinar o impacto do gerenciamento de reclamações na confiança e na lealdade do consumidor, em trocas de serviços relacionais. Para tanto, foi desenvolvido e testado um modelo teórico que retrata os inter-relacionamentos entre avaliações específicas do processo de reclamação e construtos relacionais. Desta forma, o presente estudo relaciona três importantes correntes de pesquisa: teoria da justiça, gerenciamento de reclamações e estudos sobre confiança. De modo geral, os resultados obtidos por meio da Modelagem de Equações Estruturais indicam que as percepções de justiça distributiva, interpessoal e processual afetam a percepção global de justiça e o nível de satisfação do consumidor com o gerenciamento da reclamação. A confiança do consumidor após a reclamação é influenciada diretamente pelo nível de satisfação final alcançado e pelas experiências anteriores do consumidor com a empresa. Por fim, o grau de lealdade do consumidor é influenciado pela sua confiança e pelo valor relacional.

Palavras-chaves: gerenciamento de reclamações; justiça; confiança; lealdade do consumidor; trocas relacionais.

\section{Abstract}

The main objective of this paper is to investigate the impact of the complaint handling process on the consumer trust and loyalty in the relational services context. In order to do that, a theoretical model was developed and tested. Such a model portrays the interrelationships between complaint encounter-specific evaluations and relational constructs. Thus, this study encompasses three important research streams: justice theory, complaint handling processes and trust studies. The findings, obtained by Structural Equation Modeling, confirm 10 out of 12 hypothesis stemmed from the proposed framework. More specifically, the findings indicate that distributive, procedural and interactional justice perceptions significantly affect the consumer's global justice perceptions and satisfaction with the complaint handling. Post-complaint consumer trust is directly influenced by the final satisfaction level and by the consumer previous experiences with the company. Finally, the consumer's trust and relational value affect his/her loyalty level.

Key words: complaint handling; fairness; consumer trust; consumer loyalty; relational exchanges. 


\section{INTRODUÇÃO}

Pesquisadores e profissionais de marketing têm testemunhado uma mudança de paradigma que, essencialmente, enfatiza a manutenção dos clientes atuais mediante a busca de relacionamentos mais permanentes, ao invés da aquisição de novos clientes e a realização de trocas singulares. O desenvolvimento e a manutenção de relacionamentos fortes e duradouros entre consumidores e fornecedores têm destacado a importância do conceito de lealdade que chega a ser considerada a moeda corrente no mercado do século 21 (Singh e Sirdeshmukh, 2000). Sem ela, clientes estariam dispostos a negociar com diferentes fornecedores e os relacionamentos duradouros estariam ameaçados. Desta forma, estudos que investiguem os processos e mecanismos que geram, reduzem e, enfim, influenciam a lealdade do consumidor, têm tido grande repercussão na área de marketing (Dick e Basu, 1994; Oliver, 1999; Bolton, Kannan e Bramlet, 2000).

Uma das principais vertentes de pesquisa neste sentido é o estudo sobre o gerenciamento de reclamações. O gerenciamento de reclamações se refere às interações, procedimentos e mecanismos que entram em ação, quando o consumidor registra uma queixa à empresa. Tais procedimentos podem resultar em benefícios tangíveis para o consumidor, como, por exemplo, a devolução do dinheiro ou a troca do produto com defeito, e para a empresa a lealdade do consumidor e a sua boa reputação.

Pesquisadores e praticantes têm enfatizado a importância destes processos e seus resultados. Etzel e Silverman (1981), por exemplo, sugerem que a "satisfação secundária” que se origina de um processo de reclamação não somente previne a perda de negócios, mas também pode construir maior lealdade do que a satisfação inicial com o serviço. Restaurar a satisfação do consumidor, aumentar a lealdade à marca e evitar boca a boca negativo são alguns dos resultados potenciais de um gerenciamento de reclamações bem sucedido.

Cabe ressaltar que muitos dos estudos desenvolvidos na área de gerenciamento de reclamações têm focalizado a recuperação de serviços (Bitner, Booms e Tetreault, 1990; Hoffman, Kelley e Rotalsky, 1995; Webster e Sundaram, 1998). Isto não surpreende, já que a administração de reclamações parece ser particularmente crucial para o marketing de serviços, por este apresentar algumas características peculiares, tais como a intangibilidade, difícil avaliação sobre o desempenho da empresa, maior interdependência das partes e maior contato pessoal entre funcionários e clientes. Tais características fazem do gerenciamento 
da reclamação um crítico momento da verdade na manutenção e no desenvolvimento de um relacionamento a longo prazo (Bitner, Booms e Tetreault, 1990; Berry e Parasuraman, 1991; Tax, Brown e Chandrashekaran, 1998).

No entanto, apesar do desenvolvimento de pesquisas focalizadas na resolução de reclamações, poucas pesquisas têm examinado a resolução de uma reclamação como um episódio singular dentro de um espectro maior do relacionamento entre consumidor e empresa. Neste sentido, as percepções do consumidor sobre as ações da empresa em face da reclamação podem influenciar na sua lealdade e confiança. Esta lógica é baseada em inter-relacionamentos de construtos que dizem respeito a um episódio específico (percepções sobre a resposta da empresa e satisfação pós-reclamação) e construtos relacionais (confiança e lealdade).

Com base no cenário descrito, tem-se como objetivo central deste trabalho examinar o impacto do gerenciamento de reclamações na confiança e na lealdade do consumidor, em trocas de serviços relacionais. Para isso foi desenvolvido e testado um modelo teórico que retrata os inter-relacionamentos de avaliações específicas do processo de reclamação e construtos relacionais. Desta forma, o presente estudo liga três importantes correntes de pesquisa: a teoria da justiça, o gerenciamento de reclamações e os estudos sobre confiança.

Este trabalho consta de quatro partes. A primeira trata da fundamentação teórica, do modelo teórico e das hipóteses derivadas dele. Na segunda parte são analisados os aspectos relacionados à metodologia da pesquisa. Na terceira, o modelo proposto é estatisticamente investigado a partir dos dados coletados. $\mathrm{Na}$ quarta e última parte são discutidas as contribuições deste estudo, as suas limitações e os caminhos para futuras pesquisas.

\section{Fundamentação Teórica e Hipóteses de Pesquisa}

\section{O Gerenciamento de Reclamações}

Com o crescimento do marketing de serviços nos anos 80 e o interesse pela noção de service recovery, o foco nas reclamações dos consumidores aumentou, pois profissionais de marketing perceberam que, sem a reclamação, é impossível realizar um serviço de recuperação. Assim, não mais relegada às sombras, a literatura sobre insatisfação e reclamação tem testemunhado importantes desenvolvimentos conceituais (Singh e Wilkes, 1996; Stephens e Gwinner, 1998) e empíricos (Tax, Brown e Chandrashekaran, 1998; Bolton e Lemon, 1999), principalmente no contexto norte-americano. Conseqüentemente, muitos profissionais 
e pesquisadores têm visto reclamações como oportunidades ao invés de ameaças, e o consumidor contemporâneo começa a perceber a reclamação como ação positiva em face do mercado, que passa a ser baseada menos na aceitação passiva e mais no princípio de "eu sei os meus direitos, e demando 100\% de satisfação".

No cenário brasileiro, o crescimento do interesse pela insatisfação do consumidor e o seu comportamento de reclamação deram-se principalmente pela aprovação do Código de Defesa do Consumidor ocorrida no início dos anos 90 do século anterior. Pode-se constatar que algumas empresas estão dando sinais de interesse na compreensão deste comportamento pós-insatisfação, por meio da adoção de sistemas que maximizam as oportunidades de queixas e de solicitações do cliente. A criação de departamentos ou serviços de atendimento ao consumidor, os conhecidos DAC’s ou SAC’s, é um passo importante para esta compreensão.

A reclamação é vista como um conflito estabelecido entre consumidores e empresas, em que os consumidores podem ser comparados ao litigante que apresenta seu caso a uma corte judicial, ou a um empregado que passa por uma avaliação sobre seu salário. Assim, os estudos contemporâneos sobre gerenciamento de reclamações têm oferecido evidências substanciais da adequação do conceito de justiça como base para entender o processo de reclamação e seus resultados (Goodwin e Ross, 1992; Blodgett, Hill e Tax, 1997; Tax, Brown e Chandrashekaran,1998; Smith, Bolton e Wagner, 1999). Tal conceito envolve três dimensões diferentes. Observando a ordem cronológica em que elas aparecem na literatura, a primeira dimensão explorada é a justiça distributiva, enfatizada pela teoria da eqüidade. A justiça distributiva se refere à alocação de benefícios e de custos entre as partes constitutivas de uma transação. No contexto das reclamações, as distribuições são vistas como os resultados tangíveis oferecidos pela empresa para o reclamante, como, por exemplo, a troca do produto ou o dinheiro de volta.

A segunda dimensão é a justiça processual. Esta dimensão diz respeito às políticas e aos procedimentos usados pelas empresas durante os processos de reclamações e engloba seis sub-dimensões: flexibilidade, acessibilidade, controle de processo, controle de decisão, velocidade de resposta e aceitação de responsabilidade (Thibaut e Walker, 1975; Blodgett, Hill e Tax, 1997; Tax, Brown e Chandrashekaran, 1998).

A justiça interpessoal é a terceira dimensão de justiça e envolve a maneira como os empregados tratam os consumidores e se comunicam com eles durante o episódio de reclamação. Seis subdimensões têm sido estudadas: cortesia, honestidade, empatia, esforço, oferecimento de explicações e pedido de desculpas (Clemmer, 1988; Tax, Brown e Chandrashekaran, 1998). 


\section{As Justiças Distributiva, Processual e Interpessoal e a Percepção Global de Justiça}

A percepção global de justiça é um indicador único do desempenho das empresas em face das reclamações. Acredita-se que cada uma das dimensões de justiça estudadas influenciará na avaliação final de justiça sobre as ações da empresa. Assim, tem-se o primeiro grupo de hipóteses deste trabalho:

$\mathrm{H}_{1}$ : As percepções de justiça interpessoal influenciarão positivamente a percepção global de justiça.

$\mathrm{H}_{2}$ : As percepções de justiça distributiva influenciarão positivamente a percepção global de justiça.

$\mathrm{H}_{3}$ : As percepções de justiça processual influenciarão positivamente a percepção global de justiça.

\section{As Justiças Distributiva, Processual e Interpessoal e a Satisfação com o Gerenciamento de Reclamações}

A satisfação pós-compra (ou inicial) tem sido considerada uma mediadora central, que liga crenças anteriores à compra a estruturas cognitivas pós-compra, comunicações e comportamento de recompra (Westbrook, 1987). Similarmente, a satisfação com o gerenciamento da reclamação (ou final) pode ser considerada um elemento central que media a relação entre avaliações deste gerenciamento e as atitudes e os comportamentos pós-reclamação.

De acordo com a literatura sobre justiça social, a satisfação está ligada à avaliações de justiça em várias situações de conflitos (Messick e Cook, 1983; Crosby, Evans e Cowles, 1990). Estendendo esta lógica para o gerenciamento de reclamações, é hoje amplamente reconhecido que a satisfação do consumidor com um episódio de reclamação é resultado da avaliação dos aspectos que envolvem o resultado final, o processo que levou a tal resultado e a maneira com que o consumidor foi tratado e informado durante o episódio, isto é, quão justos foram estes aspectos (Goodwin e Ross, 1992; Blodgett, Hill e Tax, 1997; Tax, Brown e Chandrashekaran, 1998; Smith, Bolton e Wagner, 1999). Assim, é proposto que cada dimensão de justiça - distributiva, processual e interpessoal - influenciará nas avaliações dos consumidores sobre sua satisfação com a resolução da reclamação.

A magnitude do efeito de cada uma dessas dimensões na satisfação tem sido um fator de divergência entre os pesquisadores da área. Enquanto Blogdett, Hill e Tax (1997) e Tax, Brown e Chandrashekaran (1998) encontraram que o efeito da justiça interpessoal na satisfação com o gerenciamento das reclamações é, de 
alguma forma, maior em magnitude do que o efeito da justiça distributiva e processual, os estudos de Goodwin e Ross (1992) e de Smith, Bolton e Wagner (1999) mostraram que a justiça distributiva explicou relativamente maior porcentagem do efeito total da justiça percebida na satisfação. Com base nestes resultados contraditórios não será estabelecida nenhuma comparação entre as três dimensões de justiça. Assim, são propostas as seguintes as hipóteses:

$\mathrm{H}_{4}$ : As percepções de justiça interpessoal influenciarão positivamente a satisfação com o gerenciamento da reclamação.

$\mathrm{H}_{5}$ : As percepções de justiça distributiva influenciarão positivamente a satisfação com o gerenciamento da reclamação.

$\mathrm{H}_{6}$ : As percepções de justiça processual influenciarão positivamente a satisfação com o gerenciamento da reclamação.

\section{A Justiça Global e a Satisfação com o Gerenciamento da Reclamação}

Da mesma forma que cada dimensão distinta de justiça, espera-se que a percepção geral de justiça em face da resolução da reclamação influencie positivamente o nível de satisfação do consumidor com o gerenciamento da reclamação. Várias pesquisas encontraram evidências da relação entre justiça global percebida e satisfação com o episódio da reclamação (Goodwin e Ross, 1992; Blodgett, Hill e Tax, 1997; Smith, Bolton e Wagner, 1999). Assim, quanto mais as ações da empresa forem percebidas como justas, mais os consumidores estarão satisfeitos em relação à maneira como as suas reclamações foram resolvidas. Tem-se, desta forma, a seguinte proposição:

$\mathrm{H}_{7}$ : A percepção de justiça global influenciará positivamente a satisfação com o gerenciamento da reclamação.

\section{A Satisfação com o Gerenciamento da Reclamação e a Confiança do Consumidor}

A confiança é definida como "um estado psicológico que compreende a intenção para aceitar vulnerabilidade baseada em expectativas positivas sobre as intenções e comportamentos do outro” (Rousseau et al., 1998, p. 395). Pesquisadores têm enfatizado o papel crucial da confiança em promover trocas relacionais (Berry, 1995; Kumar, 1996; Nooteboom, Berger e Nooderhaven, 1997). Berry (1995, p. 242) chega a afirmar que "a natureza inerente dos serviços, juntamente com a abundante desconfiança na América, posiciona a confiança como talvez a ferramenta mais poderosa do marketing de relacionamento disponível para uma 
empresa”. Recentemente, estudos teóricos (Nooteboom, Berger e Nooderhaven, 1997) e empíricos (Morgan e Hunt, 1994; Tax, Brown e Chandrashekaran, 1998; Garbarino e Jonhson, 1999) têm destacado a confiança como ingrediente fundamental para o desenvolvimento de fortes e longos relacionamentos de consumidores com as organizações.

O papel da satisfação como elemento central, ligando as percepções dos consumidores sobre o gerenciamento de reclamações às atitudes e comportamentos futuros, tem sido amplamente validado (Bitner, Booms e Tetreault, 1990; Dube e Maute, 1998; Tax, Brown e Chandrashekaran, 1998; Webster e Sundaram, 1998); no entanto o foco tem sido muito mais nas intenções imediatas de comportamento em face do produto ou serviço em questão (intenções de recompra, por exemplo) do que em variáveis como confiança, que revelam o potencial para relacionamentos de longo prazo. O trabalho desenvolvido por Tax, Brown e Chandrashekaran (1998) é um dos poucos que exploram a relação entre satisfação e variáveis relacionais. Eles encontraram uma relação significativa e positiva entre satisfação e confiança pós-reclamação, destacando o papel central da satisfação com gerenciamento de conflitos na promoção (ou redução) da confiança entre as partes envolvidas.

Isto se deve à noção de que, quando o consumidor percebe o desempenho da empresa como justo e satisfatório, os seus sentimentos de confiança (nesta) tendem a ser reforçados. Situações de conflito parecem ser ainda mais críticas neste sentido, pois há a idéia de que é nas adversidades que os parceiros são postos à prova. Desta forma, resolver satisfatoriamente uma falha na entrega de um produto, por exemplo, pode dizer mais sobre a credibilidade de determinada empresa, do que uma situação de rotina. Com base nesta lógica, supõe-se que:

$\mathrm{H}_{8}$ : A satisfação do consumidor com o gerenciamento de reclamações influenciará positivamente a sua confiança.

\section{Experiências Anteriores e a Confiança do Consumidor}

No presente estudo, espera-se que as experiências prévias do consumidor com a empresa tenham impacto na sua confiança, isto é, quando os consumidores tiveram experiências positivas com a empresa, em situações anteriores à reclamação, é provável que o seu nível de confiança na empresa seja mais alto do que quando as experiências foram negativas, independentemente da sua avaliação sobre o gerenciamento da reclamação. Isto permite supor que:

$\mathrm{H}_{9}$ : As experiências positivas anteriores com a empresa influenciarão positivamente a confiança do consumidor. 


\section{Os Antecedentes da Lealdade}

Neste estudo, a lealdade do consumidor é definida como uma intenção comportamental de manter um relacionamento duradouro com o fornecedor de serviços (Sirdeshmukh, Singh e Sabol, 2000). A partir dos resultados de vários estudos (Dube e Maute, 1998;Webster e Sundaram, 1998), propõe-se que a satisfação pós-reclamação influenciará positivamente a lealdade. A lógica deste relacionamento parece estar baseada na teoria das transações sociais, que sugere que as partes envolvidas em uma troca estão motivadas a retribuir o tratamento e os benefícios obtidos nesta troca (Thibaut e Kelly, 1959). Desta forma, os reclamantes procurarão retribuir os esforços da empresa para restaurar sua satisfação por meio da repetição da compra ou da comunicação boca a boca positiva.

Os resultados de diversas pesquisas têm fortemente demonstrado que o nível de satisfação com o gerenciamento da reclamação influencia positivamente nas intenções de recompra e recompra real dos reclamantes (Kelly, 1979; Gilly e Gelb, 1982; Martin e Smart, 1994).

O construto confiança do consumidor também deve influenciar positivamente a lealdade. O raciocínio é simples: a confiança oferece garantia quanto ao desempenho consistente e competente da empresa, assegurando que o consumidor continuará a obter valor em negócios futuros com o mesmo fornecedor. Reduzindo o risco nas trocas relacionais, a confiança contribui para dar continuidade à relação e criar sentimentos de lealdade (Ganesan, 1994). Assim, quanto maior a confiança do consumidor na empresa, maior a probabilidade de ele realizar futuros negócios com ela e de manter um relacionamento de longo prazo.

Neste sentido, os antecedentes da lealdade envolvem dois tipos de relações. A relação satisfação-lealdade, que liga atitudes episódicas a relacionais, e a relação confiança-lealdade, que liga duas variáveis consideradas relacionais. É esperado que o efeito confiança-lealdade seja dominante no contexto das trocas relacionais. De fato, em um estudo recente sobre estes efeitos em consumidores transacionais e relacionais, Garbarino e Johnson (1999) mostraram que enquanto a satisfação teve uma influência significante nas intenções futuras dos consumidores transacionais, este efeito foi insignificante para os consumidores relacionais. Para esses consumidores, muito pelo contrário, a confiança foi o maior determinante das intenções futuras. Com base nesta lógica, são estabelecidas as seguintes hipóteses:

$\mathrm{H}_{10}$ : A satisfação do consumidor com o gerenciamento de reclamação influenciará positivamente a sua lealdade.

$\mathrm{H}_{11}$ : A confiança do consumidor influenciará positivamente a sua lealdade, 
de tal forma que a sua influência será significativamente maior do que a influência da satisfação com o gerenciamento da reclamação.

Em adição à influência da confiança e da satisfação final na lealdade do consumidor, este estudo propõe a existência de um terceiro precursor da lealdade do consumidor: o nível de valor relacional. O valor relacional se refere à avaliação do consumidor quanto aos benefícios e aos custos de manter um relacionamento com a empresa (Sirdeshmukh, Singh e Sabol, 2000). A lógica aqui é a de que, mesmo quando o consumidor extrai benefícios advindos de trocas relacionais com uma empresa, se dele forem exigidos altos custos de manutenção, o relacionamento será menos atrativo e a evidência de lealdade será menor. Os resultados obtidos por Sirdeshmukh, Singh e Sabol (2000) oferecem uma evidência empírica deste raciocínio. Nestes resultados, o valor relacional emergiu como significante antecedente da lealdade do consumidor. Com base nesse raciocínio, tem-se a seguinte hipótese:

$\mathrm{H}_{12}$ : A lealdade do consumidor será positivamente influenciada pelo valor relacional.

Tendo por base a fundamentação teórica e as hipóteses estabelecidas, a Figura 1 apresenta o modelo teórico para investigar o impacto do episódio da reclamação na confiança e na lealdade do consumidor, no contexto das trocas relacionais entre consumidores e empresas. Note-se que as avaliações ligadas especificamente ao episódio de reclamação estão representadas por retângulos, enquanto os construtos considerados relacionais estão retratados de forma oval.

\section{Figura 1: Modelo para se Entender o Impacto de Episódios de Reclamação na Confiança e na Lealdade do Consumidor, no Contexto das Trocas Relacionais}

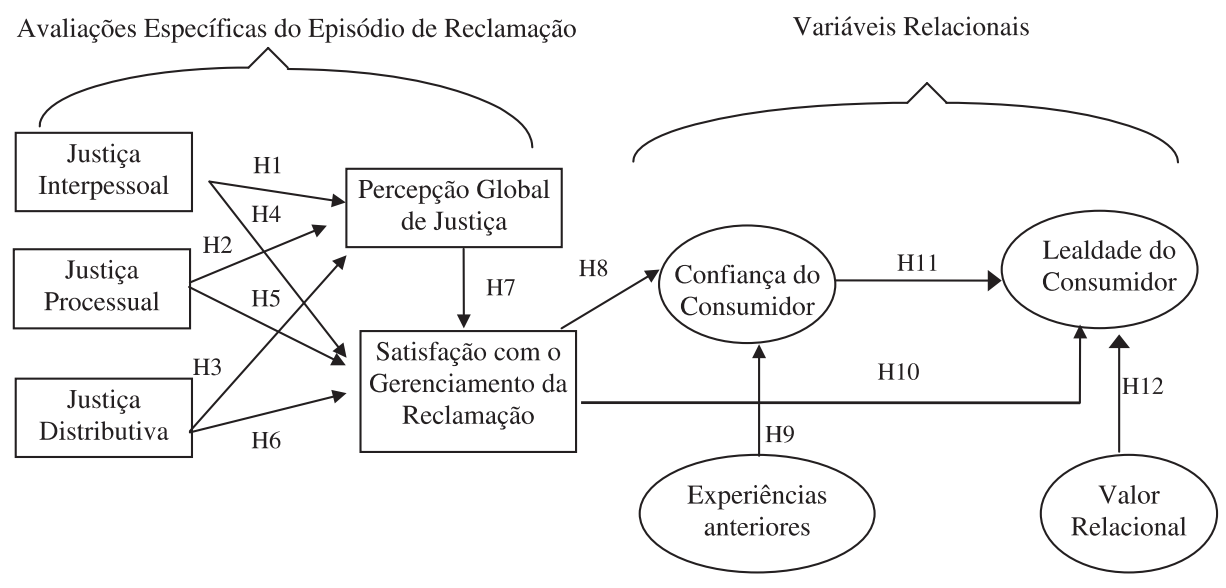




\section{O Método}

Para testar empiricamente o modelo, foi realizado um estudo descritivo de corte transversal com consumidores que se engajaram em processos de reclamação, dentro dos últimos 12 meses, tendo por base a data das entrevistas, sobre serviços que eles já haviam experimentado no passado. As reclamações foram feitas diretamente às empresas e foram, de alguma forma, respondidas.

\section{Os Procedimentos de Amostragem e de Coleta de Dados}

A amostra deste estudo foi de 224 consumidores da cidade de Porto Alegre (RS), com os quais foram feitas entrevistas pessoais. A população era constituída de assinantes da Net-Sul - TV a Cabo. Esta população foi escolhida porque a relativa complexidade do instrumento indicava que um processo aleatório de amostragem, tendo como base a população total da cidade, geraria uma taxa de retorno muito baixa. Desta forma, houve a necessidade de se adquirir uma amostra razoavelmente grande, adulta e com um padrão razoável de consumo de serviços. Os clientes da empresa Net-Sul se encaixavam neste perfil. Além disso, já existia um contato inicial entre pesquisador e empresa e o banco de dados desta empresa é um dos mais completos e atualizados do Rio Grande do Sul.

Inicialmente, foram feitos contatos telefônicos com estes clientes para que a amostra fosse selecionada. Nestes contatos, o objetivo e o patrocínio desta pesquisa foram ressaltados e perguntas-filtros foram feitas. Assim, apenas consumidores que se enquadraram no perfil desejado foram posteriormente entrevistados. Convém enfatizar que, apesar da lista ser fornecida por uma empresa fornecedora de serviços, a reclamação poderia ter sido sobre qualquer tipo de serviço, sem exceção. Desta forma, por exemplo, reclamações a respeito de um conserto de carro mal feito, atrasos em um vôo, erros na conta telefônica e problemas com um banco foram bem-vindas.

Após o contato telefônico, foram realizadas entrevistas pessoais domiciliares com as pessoas selecionadas, em horários e locais determinados por elas. Os contatos telefônicos e as entrevistas foram realizadas entre novembro e dezembro de 2000 .

\section{As Medidas}

As medidas utilizadas neste trabalho foram retiradas de vários estudos. Do estudo de Tax (1993) foram utilizados 12 itens sobre justiça interpessoal; 12 itens 
sobre justiça processual; 5 itens referentes à justiça distributiva; e 4 itens sobre satisfação com o gerenciamento da reclamação. De Goodwin e Ross (1992) e de Blodgett, Granbois e Walters (1993) foram usados 4 itens sobre justiça global. De Sirdeshmukh, Singh e Sabol (2000) foram recolhidos 4 itens sobre valor relacional; 8 itens sobre confiança do consumidor; e 1 item sobre experiências anteriores. Finalmente, de Zeithaml, Berry e Parasuraman (1996) e Sirdeshmukh, Singh e Sabol (2000) foram aproveitados 6 itens sobre lealdade do consumidor. Algumas questões foram invertidas para evitar o viés relativo à ordem das questões no questionário. Uma vez que as medidas utilizadas são originárias de estudos norteamericanos, elas foram traduzidas para a língua portuguesa por meio da técnica de tradução inversa (Dillon, Madden e Firtle, 1993). Este procedimento garantiu a manutenção do significado e da precisão das medidas.

Após a elaboração do questionário, as medidas foram submetidas a 4 doutorandos e 2 professores da área de marketing, do Programa de Pós-Graduação em Administração da Universidade Federal do Rio Grande do Sul (PPGA/UFRGS), para a validação de conteúdo, isto é, para a análise do instrumento, identificando problemas relacionados a escalas, itens, instruções e outras questões relevantes. O questionário foi modificado como requerido e um pré-teste foi feito com 15 pessoas que se enquadravam no perfil desejado, variando em grau de instrução e renda, para garantir uma comprensão irrestrita do instrumento de coleta de dados. Nenhuma mudança foi feita a partir deste pré-teste.

\section{Os Processos Estatísticos de Análise}

Os métodos estatísticos empregados para a análise dos dados foram estatísticas descritivas básicas e análise multivariada, envolvendo a modelagem de equações estruturais. Convém salientar que foram utilizados os programas de computador SPSS para as análises descritivas e o EQS, versão 5.6, para a aplicação da Modelagem de Equações Estruturais.

Entendendo-se que o objetivo central deste trabalho é testar as hipóteses elaboradas e examinar a significância estatística do modelo proposto, foi utilizada a Modelagem de Equações Estruturais. Esta abordagem oferece vários benefícios; entre eles, permite o uso de estrutura mais complexa, que pode incluir variáveis latentes e variáveis observáveis, possibilitando a análise simultânea de um grupo de inter-relacionamentos. Ela é particularmente útil, quando uma variável dependente se torna independente em relacionamentos subseqüentes (Hair et al., 1998).

Primeiramente, o modelo de medidas foi examinado. Somente após o estabelecimento da validade e da confiabilidade das medidas utilizadas é que o exame do modelo estrutural, isto é, o modelo que inclui as relações entre construtos, foi realizado. 
Esta abordagem é conhecida como two-step approach e é sugerida por vários pesquisadores (Anderson e Gerbing, 1988; Schumacker e Lomax, 1996; Kline, 1998).

Para examinar o modelo de medidas deste estudo, foi utilizada a Análise Fatorial Confirmatória. Esta análise especifica os relacionamentos entre as medidas observadas e seus construtos latentes e é essencialmente um método para avaliar a confiabilidade e a validade das medidas usadas para operacionalizar cada construto (Hair et al., 1998).

Após o exame do modelo de medidas, deu-se início ao segundo estágio de análise em que o modelo estrutural foi testado. A análise de um modelo de equações estruturais híbrido permitiu estimar empiricamente os relacionamentos estabelecidos entre os construtos latentes, combinando o modelo de medidas, previamente testado, com o modelo estrutural estimado (Kline, 1998). Uma das principais vantagens desta abordagem, que une o modelo de medidas e o modelo estrutural é, justamente, a possibilidade de se levar em consideração na análise estatística, os erros de mensuração das variáveis incluídas no modelo teórico, ao contrário das análises consideradas tradicionais, tais como a regressão múltipla e a path analysis.

Uma vez que a distribuição dos dados é considerada não normal, escolheu-se o método de estimação ERLS (iteratively reweighted generalized least squares), que não é baseado na prerrogativa de normalidade, seguindo a recomendação de Byrne (1994). Além disso, como o teste qui-quadrado é muito sensível a desvios da normalidade e a amostras superiores a 200, a análise dos valores dos quiquadrados obtidos foi feita em composição com outros critérios de ajustamento (Schumacker e Lomax, 1996; Hair et al., 1998).

\section{Análise e Discussão dos Dados}

\section{Caracterização da Amostra}

A média de idade dos respondentes é de 45 anos (d.p. = 12,21), sendo que 64\% dos respondentes são mulheres. Quarenta e três porcento dos entrevistados têm renda familiar mensal de até $\mathrm{R} \$ 2.000,00,37 \%$ de $\mathrm{R} \$ 2.000,00$ a $\mathrm{R} \$ 4.000,00$ e $20 \%$ têm renda de mais de $\mathrm{R} \$ 4.000,00$. A maioria (61\%) tem o terceiro grau completo ou incompleto e apenas $8 \%$ têm apenas o primeiro grau de instrução. A maior parte das reclamações foi feita por telefone (51\%), 36\% pessoalmente e $11 \%$ por telefone e pessoalmente. 
Com maior frequência, os consumidores haviam feito a reclamação dentro dos últimos 6 meses (64\%). O restante (36\%) havia feito entre 6 e 12 meses atrás. Isso demonstra que os episódios de reclamação foram relativamente recentes, facilitando a manutenção de respostas mais confiáveis.

Oitenta e nove porcento dos respondentes já haviam utilizado os serviços da empresa em estudo mais de cinco vezes. Isso demonstra que a maioria dos consumidores possuía um relacionamento relativamente duradouro com a empresa. As reclamações relatadas cobriram ampla gama de serviços. Os serviços mais freqüentemente citados foram bancos (25\%), telefonia fixa (16,5\%) e tevê a cabo (16\%). Entre os demais tipos de serviços estão restaurantes, oficinas mecânicas, cartões de crédito, transportes coletivos e companhias aéreas, sendo que nenhum deles recebeu mais de 7\% das indicações.

\section{Discussão sobre o Modelo de Medidas}

A partir das recomendações de vários autores (Anderson e Gerbing, 1988; Bagozzi, 1994; Hair et al., 1998; Churchill, 1999), a validade deste modelo é apoiada, basicamente, no seguinte elenco: (1) o modelo de medidas se ajusta razoavelmente bem aos dados, isto é, dentro dos índices de ajustamento considerados satisfatórios; (2) as cargas fatoriais dos indicadores nos fatores correspondentes são grandes e significativas; (3) os indicadores de um mesmo construto produzem índices de confiabilidade superiores a 0,70 e variância extraída acima de 0,50 ; (4) as correlações entre os indicadores (ou fatores) de um mesmo construto produzem evidência de validade convergente; e (5) a análise das correlações entre construtos indica validade discriminante.

Cabe salientar, ainda, que os valores genericamente aceitos para os indicadores de ajustamento são: qui-quadrado sobre graus de liberdade ( $\chi 2 / \mathrm{GL})$ igual ou inferior a 5; NFI, NNFI e CFI igual ou maior do que 0,90; RMSEA entre 0,05 e 0,08 e RMR com valores baixos (Pedhazur e Schmelkin, 1991; Hair et al., 1998).

De maneira geral, investigou-se o ajustamento do modelo aos dados coletados por meio da análise dos índices de ajustamento. Os índices alcançados demonstraram que o modelo de medida proposto para cada construto se ajustou satisfatoriamente aos dados.

A validade convergente foi apoiada, basicamente, por meio do fato de que todos os itens, sem exceção, apresentaram coeficientes fatoriais altos e significativos nos construtos a cuja mensuração se visou. Além disso, os itens associados a um mesmo construto apresentaram significativa correlação entre si. Assim, a convergência das medidas, isto é, a existência de forte correlação entre medidas destinadas a mensurar o mesmo construto, foi detectada (Gerbing e Anderson, 1988; Churchill, 1999). 
Além da validade convergente, averiguou-se a validade discriminante dos construtos propostos. Esta averiguação é particularmente importante, quando os construtos estão altamente correlacionados e são similares por natureza (Garver e Mentzer, 1999). A validade discriminante entre os construtos foi verificada por meio de um procedimento proposto por Bagozzi e Phillips (1982). Segundo estes autores, a validade discriminante entre dois construtos estimados pode ser avaliada mediante a restrição à unidade (1) do parâmetro que indica tal correlação. Um qui-quadrado significativamente mais baixo, quando a correlação não é restrita a zero, indica que os construtos não são perfeitamente correlacionados e que a validade discriminante é atingida. O resultado deste teste mostrou que todos os construtos foram encontrados devidamente distintos uns dos outros.

Finalizando a discussão sobre o modelo de mensuração, as medidas utilizadas forneceram níveis satisfatórios de confiabilidade e de variância extraída (>0,70 e >0,50, respectivamente). Isto evidencia a consistência interna entre os múltiplos indicadores de uma variável, ressaltando que estes estão, de fato, medindo um mesmo construto e explicando substancialmente seus respectivos construtos latentes (Hair et al., 1998).

\section{Discussão sobre o Modelo Estrutural}

Após o exame das medidas utilizadas para medir os construtos, o foco deste estudo se voltou para a estrutura teórica hipotetizada, que estabelece relações entre os construtos teóricos propostos. A investigação do conjunto de hipóteses foi feita, primariamente, por meio dos índices de ajustamento do modelo híbrido e da significância e magnitude dos coeficientes de regressão estimados (Hair et al., 1998; Kline, 1998).

Além disso, o coeficiente de determinação foi calculado para cada equação estrutural, similar ao que é encontrado na regressão múltipla. Ele representa a proporção de variância da variável dependente que é explicada pelas variáveis independentes (Hair et al., 1998).

A avaliação de modelos competidores é importante passo para a discussão do ajuste geral do modelo originalmente apresentado. Tomando como base os resultados de pesquisas prévias sobre o tema, identificou-se como modelo rival aquele que possui dois novos parâmetros adicionados ao modelo. O primeiro parâmetro indica um efeito direto do construto de justiça global na confiança do consumidor. Da mesma forma, a percepção sobre os princípios de justiça que norteiam as ações das empresas em face das reclamações seria peça fundamental para a redução do risco associado a futuras transações e, conseqüentemente, para o aumento das percepções de confiança (Holmes e Rempel, 1991). O segundo parâmetro diz respeito à relação causal entre confiança e valor relacional. Assim, em adição ao efeito direto da confiança na lealdade do consumidor, é proposto um segundo me- 
canismo, cujo valor relacional mediaria o efeito do nível de confiança na lealdade. Na Tabela 1 estão os indicadores de ajustamento de ambos os modelos.

\section{Tabela 1: Comparação entre Índices de Ajustamento do Modelo Original e do Modelo Rival}

\begin{tabular}{lcc}
\hline Índices de Ajustamento ${ }^{a}:$ & Modelo Original & Modelo Rival \\
$\chi 2$ (Qui-quadrado) & 1087,11( $<<0,001)$ & $1088,31(\mathrm{p}<0,001)$ \\
GL (Graus de Liberdade) & 579 & 577 \\
CFI (Comparative Fit Index) & 0,98 & 0,98 \\
NFI (Normed Fit Index) & 0,96 & 0,96 \\
NNFI (NonNormed Fit Index) & 0,98 & 0,98 \\
RMR (Root Mean Sq. Residual) & 0,17 & 0,13 \\
RMSEA (Root Mean Sq. Error of Approx.) & 0,06 & 0,06 \\
\hline
\end{tabular}

a as estimativas apresentadas são do ERLS (iteratively reweighted generalized least squares), usando EQS.

Os valores de CFI, NFI, NNFI são satisfatórios e o RMSEA está entre valores de 0,05 e 0,08, sendo, assim, aceitável. O qui-quadrado é significativo; porém, verificando-o sobre os graus de liberdade, ele produz um valor satisfatório de 1,87, bem menor que o máximo recomendado, que é 5. Comparando-se o conjunto de medidas de ajustamento obtido pelo modelo proposto e pelo modelo rival, percebe-se que, em termos de qui-quadrado, não há, virtualmente, nenhum aperfeiçoamento no modelo. Pelo contrário, a adição das duas novas relações produz um qui-quadrado um pouco maior do que o produzido pelo modelo original, com menos graus de liberdade. Os índices produzidos pelos dois modelos refletem bom ajustamento aos dados. Isto demonstra que o modelo alternativo não traz aperfeiçoamento substancial nos valores de ajustamento, quando comparado à estrutura teórica previamente estabelecida. Uma vez que nenhuma mudança positiva é gerada pelo modelo competidor e ele é menos parcimonioso, o modelo original será mantido como modelo final a ser examinado.

Os resultados da análise do modelo estrutural originalmente proposto, estão na Tabela 2. Uma vez rodado o modelo estrutural, que especifica as relações causais hipotetizadas, deve-se considerar os coeficientes padronizados de regressão e suas significâncias estatísticas. Tais coeficientes identificam a força das relações causais entre os diversos construtos do modelo, atuando diretamente na confirmação ou rejeição das hipóteses de pesquisa. 


\section{Tabela 2: Coeficientes de Regressão Estimados para as Relações Teóricas Estabelecidas no Modelo}

\begin{tabular}{lcc}
\hline Relacionamentos do Modelo & $\begin{array}{c}\text { Coeficiente Padronizado } \\
\text { de Regressão }\end{array}$ & Hipóteses \\
\hline Variável Dependente: Justiça Global & $\mathbf{0 , 3 6}(3,78)$ & $\mathrm{H}_{1}$ \\
Justiça Interpessoal & $\mathbf{0 , 2 6}(1,72)^{\mathbf{c}}$ & $\mathrm{H}_{2}$ \\
Justiça Processual & $\mathbf{0 , 3 6}(3,68)$ & $\mathrm{H}_{3}$ \\
Justiça Distributiva & $\mathbf{R}^{2}=\mathbf{0 , 8 2}$ & \\
& $\mathbf{0 , 2 1}(3,42)$ & $\mathrm{H}_{4}$ \\
\hline Variável Dependente: Satisfação com o Gerenciamento da Reclamação & $\mathrm{H}_{5}$ \\
Justiça Interpessoal & $0,08(0,06)$ & $\mathrm{H}_{6}$ \\
Justiça Processual & $\mathbf{0 , 3 4}(5,84)$ & $\mathrm{H}_{7}$ \\
Justiça Distributiva & $\mathbf{0 , 4 6}(6,06)$ & \\
Justiça Global & $\mathbf{R}^{2}=\mathbf{0 , 9 1}$ & $\mathrm{H}_{8}$ \\
& & $\mathrm{H}_{9}$ \\
\hline Variável Dependente: Confiança do Consumidor & $\mathbf{0 , 6 7}(11,82)$ & \\
Satisfação com o Gerenciamento da Reclamação & $\mathbf{0 , 1 4}(2,96)$ & $\mathrm{H}_{10}$ \\
Experiências Anteriores & $\mathbf{R}^{2}=\mathbf{0 , 4 6}$ & $\mathrm{H}_{11}$ \\
& & $\mathrm{H}_{12}$ \\
\hline Variável Dependente: Lealdade do Consumidor & $\mathbf{0 , 8 1}(10,76)$ & \\
Confiança do Consumidor & $0,11(1,61)$ & $\mathbf{0 , 1 5}(2,96)$ \\
Satisfação com o Gerenciamento da Reclamação & $\mathbf{R}^{2}=\mathbf{0 , 6 7}$ & \\
Valor Relacional & & \\
\hline
\end{tabular}

a as estimativas apresentadas são do ERLS (iteratively reweighted generalized least squares), usando EQS.

${ }^{\mathbf{b}} t$-values entre parênteses. Baseado no one-tailed test: $t$-values $>1,65=\mathrm{p}<0,05$; e $t$-values $>2,33$

$=\mathrm{p}<0,01$. Todos os coeficientes são significativos.

c coeficiente significativo ao nível de 0,05.

A partir dos resultados da Tabela 2, tem-se que, das 12 relações causais especificadas no modelo proposto, 10 foram encontradas estatisticamente significantes. Estas relações refletem o impacto: (1) da justiça interpessoal na justiça global; (2) da justiça distributiva na justiça global; (3) da justiça processual na justiça global; (4) da justiça interpessoal na satisfação; (5) da justiça distributiva na satisfação; (6) da justiça global na satisfação; (7) da satisfação na confiança do consumidor; (8) das experiências anteriores na confiança do consumidor; (9) da confiança na lealdade do consumidor; (10) do valor relacional na lealdade do consumidor. Duas relações hipotetizadas não foram significativas: a primeira diz respeito ao impacto da justiça processual na satisfação com o episódio de reclamação; a segunda se refere à influência da satisfação na lealdade do consumidor. 
De acordo com as hipóteses $\mathrm{H}_{1}, \mathrm{H}_{2}$ e $\mathrm{H}_{3}$, cada construto de justiça teve um efeito significativo e positivo na percepção global de justiça. Assim, quanto melhores as percepções de justiça interpessoal, processual e distributiva, melhores são as avaliações gerais de justiça que envolvem o episódio de reclamação. O coeficiente de determinação para este conjunto de equações, 0,82 , demonstra que estes três aspectos da justiça - interpessoal, processual e distributiva explicaram bem a variação dos escores de justiça global.

Os efeitos das percepções de justiça interpessoal, distributiva e global na satisfação com o gerenciamento da reclamação, estabelecidos nas hipóteses $\mathrm{H}_{4}, \mathrm{H}_{6} \mathrm{e}$ $\mathrm{H}_{7}$, foram confirmados pelos resultados obtidos. Já o impacto da justiça processual na satisfação final, contemplado na hipótese $\mathrm{H}_{5}$, não foi confirmado. $\mathrm{O} \mathrm{R}^{2}$ de 0,91 indica que o tratamento pessoal, os resultados tangíveis alcançados por meio da reclamação e as percepções de justiça global explicaram uma expressiva proporção (91\%) da variância nos níveis de satisfação final do consumidor.

Os resultados também confirmam as hipóteses $\mathrm{H}_{8}$ e $\mathrm{H}_{9}$, onde são estabelecidas as relações causais entre a satisfação com o gerenciamento da reclamação e a confiança do consumidor, e entre as experiências anteriores e a confiança do consumidor. $\mathrm{O} \mathrm{R}^{2}$ de 0,46 reflete razoável poder explicatório destas duas variáveis relativamente à confiança do consumidor.

Finalmente, o impacto do nível de confiança e do valor relacional na lealdade do consumidor, estabelecido em $\mathrm{H}_{10}$ e $\mathrm{H}_{12}$, foi confirmado pelos resultados; no entanto a influência da satisfação com o gerenciamento da reclamação na lealdade do consumidor $\left(\mathrm{H}_{11}\right)$ não foi estabelecida como significativa. Enquanto o nível de confiança do consumidor apresentou um efeito expressivo na sua lealdade (coeficiente de regressão de 0,81 ), a relação entre valor relacional e lealdade, apesar de significativa, apareceu, de certa forma, periférica (coeficiente de 0,15$)$. $O \mathrm{R}^{2}$ de 0,67 sugere que estes dois construtos - confiança e valor relacional - predizem, consideravelmente, a variação nos níveis de lealdade do consumidor.

Devido a estas constatações relativas à justiça processual, procurou-se entender melhor a não correspondência entre os dados e o modelo proposto. Vários motivos podem ser arrolados para explicar o fraco efeito da justiça processual. Entre eles cabe destacar: (1) a dificuldade de se avaliarem os procedimentos das empresas em face das reclamações, comparando-se com avaliações de resultados tangíveis (justiça distributiva) e tratamento pessoal recebido; e (2) as diferenças culturais existentes entre norte-americanos, onde se concentra a maioria dos estudos sobre este tema, e brasileiros. Estas diferenças estão relacionadas com a maior relevância dada pelos norte-americanos a aspectos ligados ao controle 
interno dos processos, ao uso apropriado e eficaz do tempo, à rapidez nas respostas e a outras questões relacionadas a procedimentos (Santos e Singh, 2000).

O limitado impacto da satisfação na lealdade e a posição central da confiança no contexto das trocas relacionais de serviços reforçam a mudança de ênfase proposta por Garbarino e Johnson (1999), onde a satisfação do consumidor, um construto que, por décadas, tem sido visto como precursor direto do comportamento do consumidor após a compra, dá lugar a um novo construto - confiança do consumidor - no papel de guia para as ações e as intenções futuras do consumidor em face da empresa com a qual ele já possui um relacionamento relativamente duradouro. Note-se que a satisfação tem efeito indireto na lealdade, por meio do seu efeito na confiança do consumidor.

\section{Conclusões}

\section{Implicações Acadêmicas e Gerenciais}

Sob a perspectiva acadêmica, o modelo examina algumas questões relevantes e ainda inexploradas no campo de conhecimento considerado. Entre elas cabe destacar: (1) o foco no contexto das trocas relacionais entre empresas e consumidores finais; (2) o papel da justiça nas avaliações de gerenciamento de conflitos que envolvem estas trocas; (3) a investigação das relações entre as variáveis específicas do episódio de reclamação e as variáveis relacionais; (4) a importância do conceito de confiança como antecedente da lealdade; (5) o impacto do valor relacional na lealdade do consumidor após a reclamação; (6) as interações prévias do consumidor com a empresa como antecendente do nível de confiança após a reclamação; (7) a aplicabilidade de medidas norte-americanas no contexto brasileiro; (8) a confiança como um construto multidimensional - confiança nos funcionários e confiança nas práticas gerenciais da empresa; e (9) a lealdade como um construto mais amplo, englobando mais do que somente intenções de recompra. Cabe destacar ainda que investigar o impacto das reclamações no contexto de trocas relacionais, sem incluir aspectos relativos ao histórico do relacionamento (neste caso, experiências anteriores e valor relacional), significaria omitir variáveis causais importantes para o modelo e ignorar a dinâmica que norteia as trocas mercadológicas.

Considerando o atual contexto brasileiro de pesquisa, este trabalho procura iluminar uma área de indiscutível importância para empresas e administradores, mas que parece despertar pouco interesse no campo acadêmico. São poucos os trabalhos que versam sobre a insatisfação dos consumidores (Santos, 1996; 
Chauvel, 2000) e mais raros ainda os estudos sobre o impacto do gerenciamento de reclamações no comportamento e nas atitudes do consumidor frente às empresas (Santos, 2000). Acredita-se que este campo de conhecimento é fértil e necessita de pesquisas que, como esta, sistematizem e promovam o seu entendimento, gerando, assim, uma convergência desejável entre os interesses demonstrados por praticantes e por pesquisadores.

Sob a perpectiva gerencial, o presente estudo traz várias contribuições para os profissionais de marketing. Os resultados deste estudo indicam que a mudança de foco para a criação e a manutenção de relacionamentos de longo prazo mutuamente benéficos, implica tratar os consumidores de maneira justa e satisfatória em episódios de conflito. Investimentos no gerenciamento eficiente de reclamações irão promover a confiança dos consumidores na empresa, aperfeiçoar as avaliações sobre a qualidade dos serviços prestados, gerar novos negócios e, enfim, fortalecer o relacionamento dos consumidores com a empresa.

Os administradores devem perceber o gerenciamento de reclamações como processo que envolve inúmeras questões, entre elas velocidade, flexibilidade, honestidade e cortesia, e não apenas resultados concretos, tais como restituição do dinheiro ou desconto em uma próxima compra. Além dos resultados associados a cada uma das dimensões de justiça, as correlações significativas entre elas oferecem a noção de que as empresas devem ter bom desempenho em todos os aspectos da justiça, para atingir a satisfação máxima do consumidor e manter ou incrementar a lealdade dele em face da empresa.

\section{Limitações do Estudo e Sugestões para Futuras Pesquisas}

As contribuições trazidas por este estudo devem ser ponderadas pelas limitações que as cercaram. Este trabalho utilizou uma abordagem de corte transversal, a partir de uma amostra não probabilística, composta por consumidores residentes em Porto Alegre (RS). Sob esta perspectiva, a generalização dos resultados é fortemente limitada.

Primeiramente, é reconhecido que estudos de corte transversal eliminam a oportunidade de se inferir relações de causa e efeito entre as variáveis, o que só é possível de ser alcançado a partir de estudos experimentais. A utilização de modelos estruturais pode, na melhor das hipóteses, prover algumas evidências de inferências causais (Schumacker e Lomax, 1996). Além disso, reconhece-se que a extração de inferências causais, a partir de dados obtidos em um momento único, é problemática. Desta forma, pesquisas futuras podem superar as restrições impostas pelos surveys, incluindo outras metodologias, tais como estudos experimentais e pesquisas longitudinais. 
Outro ponto que merece consideração é a idéia de que "modelos nunca são confirmados pelos dados; mas, pelo contrário, eles ganham suporte por falharem em ser desconfirmados" (Anderson e Gerbing, 1988, p. 421). Esta afirmação enaltece a lógica de que, mesmo que um dado modelo tenha obtido nível aceitável de ajustamento, há a necessidade de se investigar modelos alternativos. Este estudo deu um passo inicial importante neste sentido, comparando o modelo original com um modelo rival; contudo não foram desenvolvidos modelos qualitativamente distintos (MacCallum e Austin, 2000). No que diz respeito a este trabalho, pode-se sugerir a inclusão dos construtos confiança na benevolência e confiança na competência da empresa como variáveis alternativas às avaliações de justiça.

Finalizando, alguns tópicos de pesquisa que parecem merecer cuidado são: o estudo das relações causais e interações das dimensões de justiça; influência das diferenças individuais na importância relativa das dimensões de justiça; e a relação entre o meio usado para se fazer a reclamação e a importância das diferentes dimensões de justiça. Além disso, esforços podem ser feitos no sentido de expandir a abrangência geográfica deste estudo.

\section{ReferênCIAs Biblográficas}

ANDERSON, J. C.;

\section{GERBING, D. W.}

Structural equation modeling in practice: a review and recommended two-step approach.

Psychological Bulletin, v. 103, p. 411-23, 1988.

\section{BAGOZZI, R. P.}

Structural equations models in marketing research: basic principles. In: Principles of marketing research. Cambridge: Blackwell, 1994. p. 317-385.
BAGOZZI, R. P.; PHILLIPS, L. W.

Representing and testing organizational theories: a holistic construal. Administrative Science Quarterly, v. 27, p. 459489, 1982.

BERRY, L.

Retailers with a future. Marketing Management, v. 5, p. 39-46, Spring 1995.

BERRY, L.;

PARASURAMAN, A.

Marketing services: competing through quality. New York: The Free Press, 1991. 
BITNER, M. J.;

BOOMS, B. H.;

TETREAULT, M.

The service encounter: diagnosing favorable and unfavorable incidents. Journal of Marketing, v. 54, 71-84, Jan. 1990.

BLODGETT, J. G.;

GRANBOIS, D. H.;

WALTERS, R. G.

The effects of perceived justice on complainants' negative wordof-mouth behavior and repatronage intentions. Journal of Retailing, v. 69, n. 4, p. 399-427, 1993.

BLODGETT, J. G.;

HILL, D. J.;

TAX, S. S.

The effects of distributive, procedural, and interactional justice on postcomplaint behavior. Journal of Retailing, v. 73, n. 2, p. 185-210, 1997.

BOLTON, R. N.;

LEMON, K. N.

Dynamic model of customers' usage of services: usage as an antecedent and consequence of satisfaction. Journal of Marketing Research, v. 36, p. 171-186, May 1999.

BOLTON, R. N.;

KANNAN, P. K.;

BRAMLET, M. D.

Implications of loyalty program membership and service experiences for customer retention and value. Journal of the Academy of Marketing Science, v. 28, n. 1, p. 95-108, 2000.

BRASIL.

Leis e Decretos. Lei n. 8078, de 11 de setembro de 1990. In: Código de proteção e defesa do consumidor. São Paulo: Saraiva, 1999.

BYRNE, B. M.

Structural equation modeling with EQS and EQS/Windows: basic concepts, applications, and programming. London: Sage Publications, 1994.

CHAUVEL, M. A.

Insatisfação e queixa à empresa: investigando os relatos dos consumidores. In: ENCONTRO ANUAL DA ANPAD, 24., 2000, Florianópolis. Anais... Rio de Janeiro: ANPAD, 2000. 1 CDROM.

CHURCHILL, G.

\section{Marketing}

research: methodological foundations. Orlando: Fryden Press, 1999.

CLEMMER, E. C.

The role of fairness in customer satisfaction with services. Maryland, 1988. Thesis (Doctoral) - University of Maryland. 
CROSBY, L. A.;

EVANS, K. R.;

COWLES, D.

Relationship quality in services selling: an interpersonal influence perspective. Journal of Marketing, v. 54, p. 68-76, July 1990.

DICK, A.;

BASU, K.

Customer loyalty: toward an integrated conceptual framework. Journal of the Academy of Marketing Science, v. 22, n. 2, p. 99-113, 1994.

DILLON, W. R.;

MADDEN, T. J.;

FIRTLE, N. H.

Research in a marketing environment. St. Louis: Times Mirror, 1993.

DUBE, L.;

MAUTE, M. F.

Defensive strategies for managing satisfaction and loyalty in the service industry. Psychology \& Marketing, v. 15, n. 8, p. 775791, 1998.

\section{ETZEL, M. J.;}

SILVERMAN, B. I.

A managerial perspective on directions for retail customer dissatisfaction research. Journal of Retailing, v. 57, p. 124-136, Fall, 1981.
GANESAN, S.

Determinants of long-term orientation in buyer-seller relationships. Journal of Marketing, v. 58, p. 1-19, Apr. 1994.

GARBARINO, E.;

JOHNSON, M.

The different roles of satisfaction, trust and commitment for relational and transactional consumers. Journal of Marketing, v. 63, p. 70-87, Apr. 1999.

GARVER, M. S.; MENTZER, J. T.

Logistics research methods: employing structural equation modeling to test for construct validity. Journal of Business Logistics, v. 20, n. 1, p. 33-57, 1999.

GERBING, D. W.;

ANDERSON, J. C.

An updated paradigm for scale development incorporating unidimensionality and its assessment. Journal of Marketing Research, v. 15, p. 186-92, May 1988.

GILLY, M. C.;

GELB, $B$.

Post-purchase consumer processes and the complaining consumer. Journal of Consumer Research, v. 9, p. 323-328, Dec. 1982. 
GOODWIN, C.;

ROSS, I.

Consumer responses to service failures: influence of procedural and interactional fairness perceptions. Journal of Business Research, v. 25, p. 149-163, 1992.

HART, C. W.;

HESKETT, J. L.;

SASSER, W. E.

The profitable art of service recovery. Harvard Business Review, p. 148-156, July/ Aug. 1990.

HOFFMAN, K. D.;

KELLEY, S. W.;

ROTALSKY, H. M.

Tracking service failures and employee recovery efforts. Journal of Services Marketing, v. 9, n. 2, p. 49-61, 1995.

HOLMES, J. G.;

REMPEL, J. K.

Trust in close relationships. In: HENDRICK, C. (Ed.). Review of personality and social psychology: close relationships. London: Sage Publications, 1991. v. 10. p. 187-220.

KELLY, J. P.

Consumer expectations of complaint handling by manufacturers and retailers of clothing products. In: ANNUAL CS/D\&CB CONFERENCE, 3., 1979, [S.l.]. Proceedings... [S.l.: s.n.], 1979. p. 103-110.
KLINE, R. B.

Principles and practice of structural equation modeling. New York: The Guilford Press, 1998.

KUMAR, N.

The power of trust in m a n u f a c t ure r-reta i le r relationships. Harvard Business Review, p. 92-106, Nov./ Dec. 1996.

MACCALLUM, R. C.;

AUSTIN, J. T.

Applications of structural equation modeling in psychological research. Annual Review of Psychology, v. 51, p. 201-226, 2000

MARTIN, C. L.;

SMART, D. T.

Consumer experiences calling tollfree corporate hotlines. The Journal of Business Communication, v. 31, n. 3, p. 195-212, 1994.

MESSICK, D.;

COOK, K.

Equity theory: psychological and sociological perspectives. New York: Praeger, 1983.

MORGAN, R. M.; HUNT, S. D.

The commitment-trust theory of relationship marketing. Journal of Marketing, v. 58, p. 20-38, July 1994. 
NOOTEBOOM, B.;

BERGER, H.;

NOORDERHAVEN, N. G.

Effects of trust and governance on relational risk. Academy of

Management Journal, v. 40, n. 2, p. 308-338, 1997.

\section{OLIVER, R. L.}

Whence consumer loyalty? Journal of Marketing, p. 33-44, 1999. Special issue.

PEDHARZUR, E. J.;

SCHMELKIN, L. P.

Measurement, design, and analysis: an integrative approach. New Jersey: Lawrence Erlbaum, 1991.

ROUSSEAU, F. M. et al.

Not so different after all: a crossdiscipline view of trust. The Academy of Management Review, v. 23, p. 393-404, July 1998.

SANTOS, C. P.

Análise do comportamento do consumidor frente a experiências insatisfatórias com eletrodomésticos, na cidade de Santa Maria - RS. Porto Alegre, 1996. Dissertação (Mestrado em Administração) - Programa de Pós-Graduação em Administração, Universidade Federal do Rio Grande do Sul.

Impacto do gerenciamento de reclamações na confiança e na le- aldade do consumidor, no contexto de trocas relacionais. In: ENCONTRO ANUAL DA ANPAD, 24., 2000, Florianópolis. Anais... Rio de Janeiro: ANPAD, 2000. 1 CD-ROM.

SANTOS, C. P. dos;

SINGH, J.

Fairness in complaint resolution: a cross-national perspective, framework and hypotheses. In: AMA INTERNATIONAL MARKETING EDUCATORS' CONFERENCE, 1., 2000, Buenos Aires. Proceedings... Buenos Aires: [s.n.], 2000. 1 CD-ROM.

SCHUMACKER, R. E.;

LOMAX, R. G.

$A$ beginner's guide to structural equation modeling. New Jersey: Lawrence Erbaum, 1996.

SINGH, J.;

WILKES, R. E.

When consumer complain: a path analysis of consumer complaint responses estimates. Journal of the Academy of Marketing Science, v. 24, p. 350-365, 1996.

SINGH, S.;

SIRDESHMUKH, D.

Agency and trust mechanisms in consumer satisfaction and loyalty judgments. Journal of the Academy of Marketing Science, v. 28, n. 1, p. 150-167, 2000. 
SIRDESHMUKH, D.;

SINGH, S.;

SABOL, B.

Impact of frontline employee behaviors and management practices on consumer trust, value and loyalty in relational services exchanges. Cleveland, Case Western Reserve University, 2000. Work paper.

SMITH, A. K;

BOLTON, R. N.;

WAGNER, J.

A model of customer satisfaction with service encounter involving failure and recovery. Journal of Marketing Research, v. 36, p. 356-372, Aug. 1999.

STEPHENS, N.;

GWINNER, K. P.

Why don't some people complain? A cognitive-emotive process model of consumer complaint behavior. Academy of Marketing Science, v. 26, n. 3, p. 172-189, 1998.

TAX, S. S.

The role of perceived justice in complaint resolutions: implications for services and relationship marketing. Arizona, 1993. Thesis (Ph.D. in Administration) - Arizona State University.
TAX, S. S.;

BROWN, S. W.;

CHANDRASHEKARAN, M.

Customer evaluations of service complaint experiences: implications for relationship marketing. Journal of Marketing, v. 62, p. 60-76, Apr. 1998.

THIBAUT, J.;

KELLY, H. H.

The social psychology of groups. New York: John Wiley \& Sons, 1959.

THIBAUT, J.;

WALKER, L.

Procedural justice: a psychological analysis. Hillsdale, NJ: Lawrence Erlbaum, 1975.

WEBSTER, C.;

SUNDARAM, D. S.

Service consumption criticality in failure recovery. Journal of Business Research, v. 41, p. 153-159, 1998.

WESTBROOK, R. A.

Product/consumption-based affective responses and postpurchase processes. Journal of Marketing Research, v. 24, p. 258-270, Aug. 1987.

ZEITHAML, V. A.;

BERRY, L. L.;

PARASURAMAN, A.

The behavioral consequences of service quality. Journal of Marketing, v. 60, p. 31-46, Apr. 1996. 